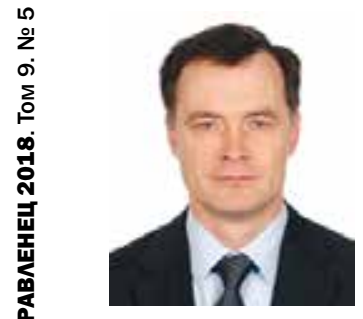

ШАСТИТКО АнАрей Евгеньевич Аоктор экономических наук, профессор, заведующий кафедрой конкурентной и промышленной политики МГУ им. М.В. Аомоносова; Аиректор Центра исследований конкуренции и экономического регулирования

\section{Российская академия} народного хозяйства и государственной службы при Президенте РФ

119571, РФ, г. Москва, пр. Вернадского, 82, стр. 1

Tел.: (495) 393-52-37

E-mail: aes99@yandex.ru

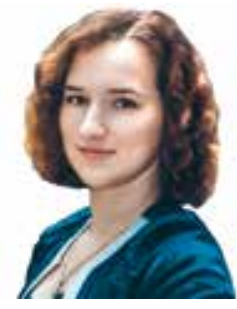

ШПАКОВА Анастасия Андреевна

Аспирант экономического факультета МГУ им. М. В. Аомоносова; младший научный сотрудник Центра исследований конкуренции и экономического регулирования

Российская академия народного хозяйства и государственной службы при Президенте РФ 119571, РФ, г. Москва, пр. Вернадского, 82, стр. 1 Teл.: (495) 393-52-37

E-mail: aa-shpakova@mail.ru

\section{Ключевые слова}

КОНТРАКТНЫЕ ОТНОШЕНИЯ

ЭЛЕКТРОННЫЙ ДОКУМЕНТООБОРОТ

ТРАНСАКЦИОННЫЕ ИЗДЕРЖКИ

РАСПРЕДЕЛИТЕЛЬНЫЕ ЭФФЕКТЫ

ЮРИДИЧЕСКИ ЗНАЧИМЫЙ

ДОКУМЕНТООБОРОТ

РОУмИНГ

JEL classification

D23, L14, L15

\section{Электронный документооборот \\ в контрактных отношениях}

\section{Аннотация}

Распространение цифровых технологий повышает актуальность исследования новых способов организации межфирменного обмена юридически значимыми документами. Статья посвящена вопросам взаимосвязи контрактных отношений, механизмов управления трансакциями, дискретными структурными альтернативами организации документооборота. Методологическую основу исследования составили положения неоинституциональной экономической теории, включающие теорию трансакционных издержек и теорию контрактов. В работе обсуждаются экономические эффекты от распространения электронного документооборота (ЭдО) на основе объяснения его влияния на различные виды трансакционных издержек. Вопрос совместимости форматов электронных документов помимо технической имеет экономическую составляющую, выражающуюся в выработке отраслевого стандарта на рынке услуг операторов ЭД0 и в указанных выше эффектах, возникающих в процессе контрактации. Выбор способа обмена юридически значимыми документами может быть существенным фактором при заключении контракта, особенно в условиях несовпадения этих способов у участников обмена. Особое внимание уделено экономическим аспектам обеспечения совместимости стандартов электронного документооборота в построении договорных отношений в их целостности, начиная с разработки условий контракта и завершая финальными расчетами по результатам поставок товаров и оказанным услугам.

\section{ВВЕДЕНИЕ}

Коммуникация - обмен экономически значимой информацией - один из ключевых аспектов контрактных отношений в условиях ограниченной рациональности контрагентов, степень которой в свою очередь зависит от того, каким образом организованы информационные потоки. Сами условия обеспечения координации действий, планов, ожиданий участников обмена тесно связаны с выбранными способами коммуникации, определяющими уровень и структуру трансакционных издержек [5. С. 473]. Быстрые технологические изменения в самых разных сферах отношений включили в повестку дня вопрос о применении цифровых технологий в межорганизационном документообороте, в том числе электронном документообороте (далее - ЭДО) между компаниями.

Исследование вопросов взаимосвязи между контрактными отношениями, механизмами управления трансакциями и способом организации обмена документами - в первую очередь юридически значимыми - пока не нашло должного отражения в экономической литературе. Вместе с тем следует отметить работы, которые затрагивают отдельные аспекты указанной проблемы, например, исследование трансформации отношений между поставщиками и покупателями в результате внедрения технологий электронного обмена данными и документами [16] или анализ значения технологий ЭДО в снижении негативного влияния фактора неопределенности в деятельности фирм [10]. На восполнение пробелов в этом комплексном вопросе и направлена данная работа, в которой предполагается рассмотреть организацию ЭДО между компаниями через призму дискретных структурных альтернатив и других аспектов, исследуемых в рамках новой институциональной экономической теории.

В первой части статьи раскрываются масштабы и обозначены преимущества, которые сулит применение электронного документооборота. Во второй части особое внимание уделяется сравнительному анализу дискретных 
Andrey Ye. SHASTITKO

Dr. Sc. (Econ.), Professor,

Head of Competition Policy and Industrial Policy Dept.

(Lomonosov Moscow State University);

Director of the Centre for Studies of Competition and Economic Regulation linkage between contractual relationship, transaction management mechanisms and discrete institutional alternatives of document interchange. The methodological basis of the study is the provisions of the neo-institutional economic theory, including transaction cost theory and contract theory. The paper addresses the economic effects produced by the spread of electronic document interchange (EDI) through its impact on various types of transaction costs. In addition to the technical component, the issue of compatibility of electronic document formats also has the economic component expressed in the development of an industry standard in the market for EDI service operators and in the above-mentioned effects arising in the process of contracting. The choice of the way of interorganizational document interchange has a significant role in the contracting process, especially in the conditions of the difference in counterparts' methods of organizing the document flow. The authors discuss the economic aspects of the compatibility of the standards of the electronic documents for interorganizational exchange in the contracting process from constructing contractual arrangements to final paying for goods and services delivered.

структурных альтернатив межфирменной коммуникации в части обмена юридически значимыми документами. В заключении сформулированы основные выводы и обозначены направления дальнейших исследований.

\section{МАСШТАБЫ И ПРЕИМУЩЕСТВА ЭЛЕКТРОННОГО ДОКУМЕНТООБОРОТА}

В рамках процесса контрактации (начиная с обсуждения условий контракта и завершая финальными расчетами по результатам поставок товаров и оказанным услугам) между покупателями и продавцами неизбежно возникают трансакционные издержки, которые проявляются во множестве форм и зависят от способа организации взаимодействия между компаниями. Данные издержки можно рассматривать во временном разрезе, что реализовано Дж. Уоллисом и Д. Нортом [15. Р. 98] в их классификации, отражающей распределение издержек по этапам контрактации:

- ex ante - период до заключения контракта, в котором существуют трансакционные издержки, включающие затраты на получение информации о ценах, качестве товара, надежности контрагента и возможных альтернативах. В данном случае акцент будет не на технологиях ЭДО, хотя они могут применяться для подачи официальных запросов, например о ценах и номенклатуре товара, а на цифровых технологиях, используемых для поиска информации и ее систематизации;

- ex interim - этап заключения контракта, на котором возникают издержки, связанные с оформлением и передачей (пересылкой) документов, нотариальным заверением, осуществлением расчетов и т.д. На данном этапе технологии ЭДО играют важную роль, поскольку позволяют ускорить процесс заключения контракта, сократив время на передачу и подписание документов;

- ex post - этап исполнения контракта и постконтрактных отношений, на котором издержки связаны с осуществлением контроля, решением возникающих споров и др. В процессе исполнения контрактного соглашения применение ЭДО обеспечивает оперативный обмен документацией и сокращает

\section{The Russian Presidential Academy of National Economy and Public Administration 119571, RF, Moscow, Vernadskogo Ave., 82, building 1 Phone: (495) 393-52-37 \\ E-mail: aes99@yandex.ru}

\section{Anastasiya A. SHPAKOVA}

Postgraduate of Faculty of Economics (Lomonosov Moscow State University); $J$ r. Researcher of the Centre for Studies of Competition and Economic Regulation

\section{The Russian Presidential Academy of National Economy and Public Administration 119571, RF, Moscow, Vernadskogo Ave., 82, building 1 Phone: (495) 393-52-37 \\ E-mail: aa-shpakova@mail.ru}

\section{Keywords}

CONTRACTUAL RELATIONSHIP

ELECTRONIC DOCUMENT INTERCHANGE

TRANSACTION COSTS

DISTRIBUTION EFFECTS

LEGALLY RELEVANT DOCUMENT INTERCHANGE ROAMING

JEL classification 
число ошибок в расчетных документах при их автоматической обработке [13. Р. 13], что снижает часть издержек по обеспечению взаимодействия с партнером и мониторингу его деятельности.

Таким образом, ЭДО играет важную роль при обеспечении расчетных и иных часто повторяющихся операций в процессе исполнения контрактов, а также при их заключении. Далее мы подробнее рассмотрим влияние технологий ЭДО юридически значимых документов на разные виды трансакционных издержек. Однако в первую очередь отметим масштабы и основные эффекты от внедрения технологий ЭДО, которые и приводят ко все большему распространению данной формы документооборота, но пока безотносительно разделения ЭДО на внутрифирменный и межфирменный.

Основной причиной внедрения ЭДО является экономия ресурсов (трудовых, временных и финансовых), высвобождающихся при замене бумажного документооборота электронным. Преимущества ЭдО перед традиционными формами выражаются в экономии на статьях затрат, составляющих трансакционные издержки по обращению официальной документации между контрагентами, что подтверждается соответствующими эмпирическими исследованиями $[9-11 ; 13 ; 16 ; 17]$. Это проявляется в следующем:

- снижение трудовых и временных затрат сотрудников на работу с документами, что приводит не только к повышению оперативности работы с информацией, но и к экономии трудозатрат работников и, соответственно, фонда заработной платы;

- экономия на канцелярских расходах и на пересылке корреспонденции;

- сокращение числа ошибок за счет автоматизированной сверки счетов, исключение дубликатов и потери документов за счет единой системы регистрации;

- повышение оперативности получения информации, сокращение времени, затрачиваемого на согласование и принятие решений, а также на доведение решения до исполнителей;

- установление связей между документами, упрощение поиска документов и оперативный доступ к информации;

- контроль доступа к документу и разграничение прав на операции с документами за счет реализации различных уровней доступа, а также криптографическая защита и возможность определения источника утечки информации;

- повышение прозрачности бизнес-процессов и исполнительской дисциплины, появление информации, способствующей оптимизации управленческих процессов в компании;

- иные эффекты от внедрения ЭДО, в том числе экономия на складах для хранения архивной документации, сокращение экологических последствий и т.д.
В качестве примера преимущества электронного документооборота по сравнению с бумажным приведены расчеты Всемирного банка, основанные на данных 165 стран, относительно затрат времени на обеспечение оформления и совместимости документов при трансграничных сделках в трех вариантах документооборота: полностью бумажном, смешанном электронно-бумажном (когда часть документов подается в электронной форме, а часть в бумажной) и полностью электронном (рис. 1). Как мы видим, электронный формат оформления документов позволят почти в 4 раза сократить время оформления трансакции для экспортера и в 4,4 раза - для импортера.

О масштабах распространения ЭДО в России свидетельствуют следующие данные Росстата (рис. 2). Две трети организаций в стране (66\%) использует системы внутреннего электронного документооборота, причем эта величина остается на данном уровне на протяжении последних пяти лет. Подобную стабильность можно объяснить тем, что большинство компаний, в которых внедрение внутреннего электронного документооборота экономически обосновано, уже осуществили его, а другая часть компаний пока не чувствует потребности в данной технологии.

В то же время доля организаций, использующих электронный обмен данными между своими и внешними информационными системами, продолжает увеличиваться. Однако следует уточнить, что этот показатель не отражает, насколько велика доля ЭДО в общем документообороте, поскольку в каждой из организаций, положительно ответивших на данный вопрос, она может быть различной [6]: одни обмениваются счетами-фактурами и прочей финансовой документацией с контрагентами, другие только сдают отчетность в электронном виде. 3начительный рост распространенности обмена электрон-

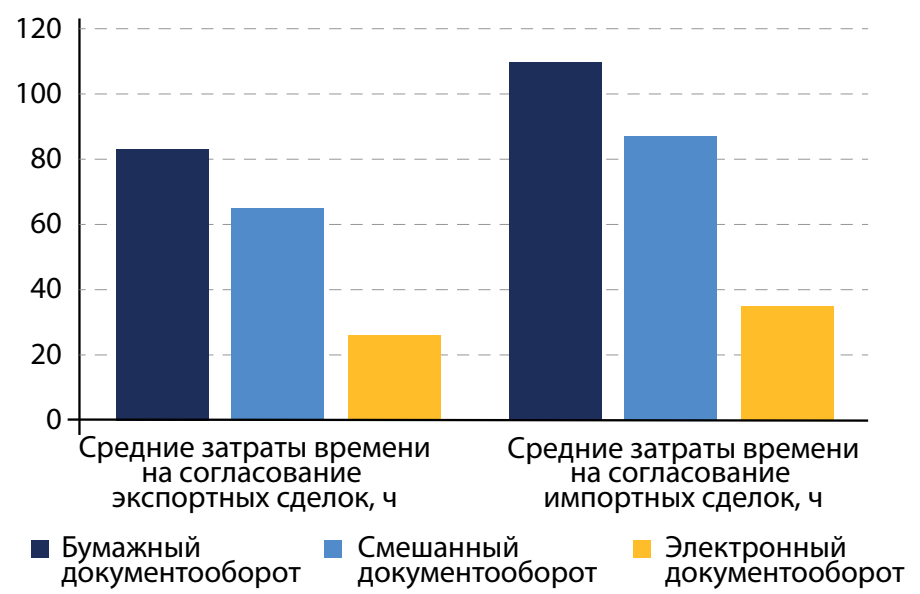

Рис. 1. Зависимость времени оформления трансграничных сАелок при разных формах документооборота

Источник: Doing Business. A World Bank Group Flagship Report / International Bank for Reconstruction and Development - The World Bank, 2017. URL: http://russian.doingbusiness.org/ /media/WBG/DoingBusiness/Documents/Annual-Reports/English/DB17-Full-Report.pdf 


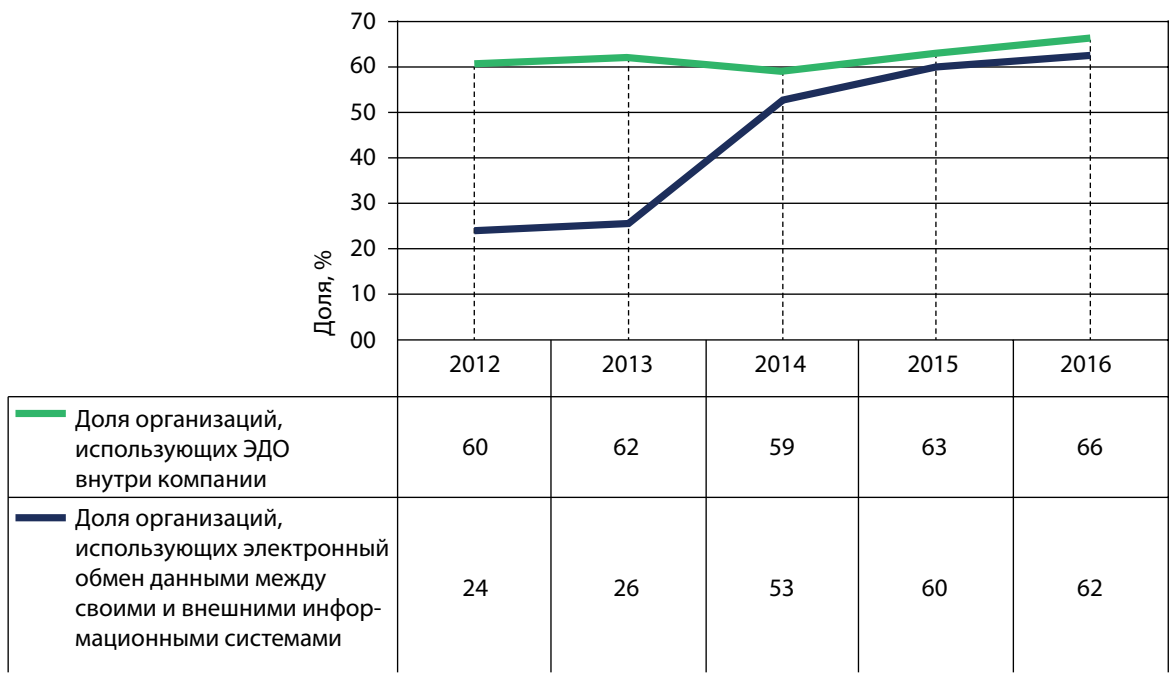

Рис. 2. Аинамика распространения ЭАО в России, 2012-2016 гг.

Составлено по: Российский статистический ежегодник: стат. сб. / Росстат. М., 2017. раметрам эти альтернативы уступают технологиям ЭДО:

- факс требует все тех же канцелярских затрат, уступает ЭДО в оперативности и времязатратности, практически не приспособлен к автоматизированной обработке содержащейся в документе информации;

- телефонная связь обеспечивает оперативное информирование контрагента (например, о заказе или доставке груза), однако не имеет о юридической значимости и для применения требует высокого уровня доверия между контрагентами, не может заменять бумажный документооборот и служит как дополнительный канал коммуникации;

ными документами с внешними системами и контрагентами в течение 2014 г. связан прежде всего с реформами Федеральной налоговой службы России, направленными на стимулирование ЭДО (распоряжение ФНС России от 30 июня 2014 г. № 99), и созданием условий для его распространения.

Не так давно появились работы, рассматривающие роль и распространение ЭДО среди компаний-участников производственной (продовольственной) цепи или цепи поставок (supply chain). Например, согласно эмпирическому исследованию, проведенному на основе интервью с представителями различных звеньев цепи поставок в автомобильной отрасли Марокко, в частности, с поставщиками комплектующих разного уровня, производителями, импортерами, дилерами, помимо указанных преимуществ, ЭДО позволяет оптимизировать логистические процессы [12]. Отдельно авторы отмечают тот факт, что благодаря применению ЭДО улучшаются условия для внедрения в производстве метода «поставки точно в срок» (just-in-time), который, как известно из опыта исследований предприятий в японской экономике уже в конце XX века, позволяет значительно сэкономить на складских расходах и запасах и является одним из источников конкурентных преимуществ японских автопроизводителей на мировом рынке [1].

В указанном выше исследовании было определено, что при движении относительно производственных предприятий вверх по производственной цепи компании склонны к более активному использованию ЭДО, в то время как вниз по цепи к дистрибьюторам автомобилей технологии ЭДО распространены значительно меньше, потому что, как объясняют авторы исследования, многие дистрибьюторы являются представителями малого и среднего бизнеса, которые ограничены в доступе к необходимому оборудованию и найму технически подготовленных работников по организации работы систем ЭДО [12]. Соответственно, они используют в своей работе аналоги (факс, e-mail, телефон). Рассмотрим, по каким па-
- e-mail наиболее конкурентоспособный аналог ЭДО, более того, формат электронной почты встроен и используется в самих системах электронного документооборота. Использование в целях документооборота e-mail без привлечения операторов ЭДО возможно даже для юридически значимых документов, оформленных в соответствии с законодательством и подписанных соответствующим типом электронной подписи, однако есть правовые ограничения. Так, в Российской Федерации согласно приказу ФНС России № ММВ-7-6/253@ от 20 апреля 2012 г. ${ }^{1}$ обмен счетами-фактурами в электронном виде осуществляется только через операторов электронного документооборота, включенных в сеть доверия ФНС России. При нарушении данной нормы счет-фактура не будет признан действительным;

- иные цифровые технологии обмена файлами (мессенджеры, облачные хранилища с совместным доступом и др.), не интегрированные в комплексную систему документооборота организации. С одной стороны, эти технологии во многом позволяют реализовывать преимущества электронного обмена данными по сравнению с бумажным документооборотом, однако, в силу их невстроенности в общую систему документооборота компании, они не могут привести к максимально возможному уровню эффективности, достигаемому при ЭДО. Также отметим, что этот способ не подходит, например, для пересылки юридически значимых первичных бухгалтерских документов в электронной форме согласно уже упомянутому приказу ФНС.

На текущий момент межкорпоративный электронный документооборот распространен в мире значительно в меньшей степени, чем внутриорганизационный. Однако мировые темпы прироста его объемов действительно высоки. По оценкам экспертов, только в одной

${ }^{1}$ Об утверждении Временного положения о Сети доверенных операторов электронного документооборота и Временного положения о порядке присоединения к Сети доверенных операторов электронного документооборота: приказ ФНС России от 20 апреля 2012 г. №MMB-7-6/253@ (ред. от 4 апреля 2016 г.). 
из областей применения безбумажных технологий в документообороте - обмене электронными счетами и счетами-фактурами (e-invoicing), более 400 млрд счетов и счетов-фактур ежегодно создаются по всему миру, и при этом только 36 млрд ${ }^{1}$ являются электронными, однако рынок e-invoicing ежегодно растет примерно на 10-35\% в зависимости от страны [14. Р. 2]. Степень распространения межкорпоративного ЭДО среди компаний зависит не только от страны - в Скандинавских странах этот показатель значительно выше других европейских стран $[14 ; 18]$, но и от отрасли и масштаба организаций - например, банковский сектор с высокой степенью внедрения ЭДО и строительство - с относительно низкой [9].

В развитии межкорпоративного ЭДО заинтересован, с одной стороны, бизнес - из-за территориальной удаленности контрагентов, когда пересылка и подписание документов либо занимают много времени, либо дорого стоят, с другой стороны, государство, которое работает над развитием законодательства в области обмена формализованными документами и стимулирует организации к взаимодействию с государственными органами преимущественно в электронном формате [7. С. 22]. В частности, в программе «Цифровая экономика Российской Федерации» планируется доведение доли форм отчетности организаций, предоставляемых однократно только в электронном виде, из которых треть формируется автоматически ${ }^{2}$, к 2025 г. до 100\%. В результате применения ЭДО между организациями, в том числе между компаниями, значительно сокращаются экономические расстояния, несмотря на географическую удаленность контрагентов.

\section{СТРУКТУРНЫЕ АЛЬТЕРНАТИВЫ ОРГАНИЗАЦИИ МЕЖФИРМЕННОГО ДОКУМЕНТООБОРОТА}

Перейдем к рассмотрению экономических эффектов от распространения ЭДО относительно процесса контрактации. Отметим, что внедрение ЭДО не обеспечивает автоматическое сокращение издержек, хотя преимущественно наблюдается положительный эффект [8; 16]. Вместе с тем есть статьи расходов, которые возрастают в результате внедрения ЭДО. Прежде всего, это значительные первоначальные инвестиции на установку и подключение системы, включающие также стоимость лицензии на программное обеспечение, создание необходимой ИТ-инфраструктуры, закупку сертификатов электронной подписи. Средний срок окупаемости систем обеспечения межкорпоративного ЭДО составляет 0,5-1,5 года [13. Р. 5].

Для определения того, какие координационные и распределительные эффекты возникают для участников обмена вследствие выбора способа организации документооборота при заключении контракта, рассмотрим ситуацию взаимодействия покупателя и поставщика

\footnotetext{
${ }^{1}$ В данную величину включается документооборот не только между организациями (B2B), но и B2G \& G2B.

${ }^{2}$ Программа «Цифровая экономика Российской Федерации», утв. распоряжением Правительства РФ от 28 июля 2017 г. № 1632-р. C. 54-55.
}

(продавца), при этом не затрагивая вопрос ЭдО с физическими лицами, что выходит за рамки исследования. Несмотря на то что особенности взаимодействия и необходимые документы варьируются в зависимости от длительности отношений, формы поставки, вида товара и т.д., разберем общие стратегии поведения, которые доступны участникам обмена в зависимости от первоначально принятых в организациях способов документооборота.

До вступления в контрактные отношения компании осуществляют поиск контрагента и уточнение всех условий сделки. На их выбор помимо таких традиционных критериев, как цена и качественные характеристики самого товара, может оказывать влияние и вопрос организации обращения документов с контрагентом. Если это единичная сделка, требующая небольшого числа документов, то весомость этого фактора незначительна. В противном случае, при выстраивании долгосрочных отношений и необходимости налаживать/оптимизировать постоянный документопоток способ организации документооборота между компаниями будет иметь большее значение.

Возможны следующие ситуации:

1. Обе организации используют бумажный документооборот.

2. Один из контрагентов сопровождает свою деятельность электронным документооборотом, а другой бумажным.

3. Оба участника используют для организации документооборота с контрагентами электронный формат (ЭДО):

3.1) у контрагентов общий оператор ЭДО;

3.2) у контрагентов разные операторы ЭДО, между которыми есть соглашение о роуминге ${ }^{3}$;

3.3) у контрагентов разные операторы ЭДО, между которыми отсутствует роуминг.

Прежде чем рассматривать все ситуации, определим, кто такие операторы ЭДО и в чем состоит их роль. Согласно определению ФНС России, оператор электронного документооборота - «организация, обладающая достаточными технологическими, кадровыми и правовыми возможностями для обеспечения юридически значимого документооборота счетов-фактур в электронном виде с использованием электронной подписи» (приказ ФНС России №MMB-7-6/253@ от 20 апреля 2012 г.). Иными словами, операторы ЭДО - это коммерческие компаниипосредники, которые предоставляют услуги по обмену электронными юридически значимыми документами по телекоммуникационным каналам связи.

По состоянию на март 2018 г. реестр ФНС РФ содержит 50 организаций, включенных в Сеть доверенных операторов ЭДО 4 , что позволяет им предоставлять услуги по

\footnotetext{
${ }^{3}$ Роуминг - технология обмена юридически значимыми электронными документами между разными операторами ЭДО. URL: http://roseu.org/roaming.

${ }^{4}$ Электронные счета-фактуры. URL: https://www.nalog.ru/rn77/
} taxation/submission_statements/el_count/. 
передаче электронных счетов-фактур и обеспечению их юридической значимости. Кроме того, доверенные операторы ЭДО обязаны обеспечивать взаимодействие продавца и покупателя при выставлении и получении электронных счетов-фактур независимо от оператора или системы ЭДО на другой стороне сделки'.

Примером операторов ЭДО могут служить такие компании, как «Директум», «ТаксНет», «Тензор», «Такском», «КОРУС Консалтинг СНГ», ПФ «СКБ Контур» и др., которые в числе своих услуг предоставляют сервис обмена электронными документами с внешними контрагентами и возможность интеграции указанного сервиса с учетными программами и системами внутреннего документооборота организации.

Перейдем к анализу возможных ситуаций, связанных с различными вариантами обеспечения документооборота между контрагентами.

В первом случае обе организации используют бумажный документооборот, при этом основные издержки обмена информацией будут связаны с длительностью доставки, согласования и иными операциями с документами в печатной форме, хотя внутри компаний вполне могут быть установлены системы ЭДО, не имеющие выхода на межкорпоративный уровень, т.е. обеспечивающие только внутренние процессы документационного обеспечения. Сократить время документооборота между организациями позволяет переход на электронный формат взаимодействия, однако с этим связаны не только издержки, упомянутые выше, но и ряд других сложностей, которые отражены в ходе рассмотрения последующих ситуаций.

Согласно второму варианту один из контрагентов выстраивает взаимодействие с партнерами посредством электронного обмена документацией, а другой - на основе традиционного бумажного делопроизводства. В этой ситуации на границе организаций возникает проблема выбора предпочтительного варианта документационного обеспечения взаимодействия, решение которой приводит к возникновению распределительных эффектов, заключающихся в определении определение стороны, которая понесет дополнительные трансакционные издержки по обеспечению обмена официальной документацией: будет ли это только одна из фирм, если да - то какая, или будет найден компромиссный вариант и издержки распределятся относительно равномерно.

Выбор варианта решения будет зависеть от нескольких факторов, в числе которых стратегия, выбранная каждым контрагентом, наличие технологического лидерства у одной из сторон, но в первую очередь симметричность распределения переговорной силы среди контрагентов.

Несмотря на то что форма документооборота является одним из условий организации обмена между контрагентами, она выступает не источником переговорной

${ }^{1}$ Об утверждении Порядка выставления и получения счетов-фактур в электронной форме по телекоммуникационным каналам связи с применением усиленной квалифицированной электронной подписи: приказ Минфина России от 10 ноября 2015 г. № 174н. силы, как в ситуации с правилами обмена и стратегиями поведения контрагентов [6], а неценовой характеристикой, в отношении которой контрагенты могут использовать свое преимущество в переговорах.

Так, компании с относительной симметричной переговорной позицией будут искать компромиссное решение (вариант ситуации 3.2). В условиях, когда есть асимметрия переговорной силы, например, в сделке участвуют крупный покупатель и множество более мелких поставщиков (ситуация, распространенная в ритейле с участием крупных розничных сетей), у покупателя может быть преимущество в переговорной силе, а значит, и возможность : влиять на своих поставщиков в их выборе оператора межкорпоративного электронного документооборота, вплоть до указания данного пункта в договоре, что можно в отдельных случаях трактовать как условия ограничения конкуренции.

Так, в исследовании Б. Коха описываются основные стратегии, которых придерживаются крупные компании по стимулированию своих контрагентов к переходу на электронный формат обмена документами, в частности счетами [13. Р. 6-7]. Эти стратегии содержат различные методы стимулирования партнеров, начиная от обычных переговоров и до использования компанией своего переговорного преимущества для включения требований по электронному формату документооборота в условия договора. Но наиболее радикальным методом выступает наложение штрафов на контрагентов за предоставление счетов на бумажном носителе, что ложится дополнительными издержками на партнеров данной компании. В этой связи возникает вопрос: является ли такая договорная практика правомерной и не связана ли она с созданием дискриминационных условий, которые предполагают применение требований, не обусловленных различиями в издержках (по аналогии с различными ценами, которые не обусловлены различиями в издержках)? Однако принципиально важно здесь то, что отсутствие совместимости выступает одним из источников дополнительных издержек в контрактных отношениях, устранение которого сопровождается и решением вопроса о распределении бремени этих издержек (и связанных с ними рисков) между компаниями.

Несмотря на наличие преимущества в переговорной силе, компании не всегда применяют его в отношении организации ЭДО, в связи с чем существует такое явление, как мультиоператорность, когда компания устанавливает одновременно две и более системы для обеспечения межкорпоративного обмена электронными документами с основными поставщиками, использующими услуги разных операторов ЭДО. Данный вариант влечет за собой, с одной стороны, снижение трансакционных издержек по переговорам с новыми партнерами, у которых есть хотя бы одна из установленных в компании систем ЭДО с контрагентами (а в ряде случаев - и снижение регуляторных издержек), но, с другой стороны, эта стратегия повышает издержки, связанные с обслуживанием каждой новой системы, дополнительными затратами труда и вре- 

мени сотрудников, которым приходится одновременно работать с несколькими операторами в разных интерфейсах. Причиной, по которой этот вариант существует, является именно отсутствие совместимости между форматами электронных документов разных операторов ЭДО, когда компании удобнее установить несколько систем, чем добиваться у имеющегося оператора ЭДО настройки роуминга с другим контрагентом.

Третий тип ситуаций основан на том, что оба контрагента используют в своей работе электронный документооборот. На первый взгляд, очевиден выбор в пользу ЭДО, поскольку обе компании имеют соответствующие технологические возможности и эти технологии объективно позволяют экономить на некоторых типах издержек. И это справедливо для случая, когда у компаний общий оператор ЭДО либо установлены одинаковые системы внутреннего документооборота с возможностью межкорпоративного обмена файлами со сторонним участником, у которого установлена аналогичная система.

При наличии разных внутренних систем электронного документооборота и отсутствии у каждого из участников обмена ранее привлеченного оператора по услугам межкорпоративного электронного документооборота возможен выбор общей компании-оператора по обеспечению роуминга, работающего с обеими системами электронного документооборота. Это наиболее удобный случай, обеспечивающий минимальные издержки документооборота с обеих сторон и не требующий дополнительных затрат по обеспечению координации действий в целях создания условий для исполнения контракта, кроме издержек выбора общего оператора ЭДО.

Более сложное положение складывается, когда у компаний уже имеются разные операторы ЭДО, между которыми может быть заключено соглашение о роуминге, но оно может и отсутствовать. В 2012 г. ассоциацией «РОСЭУ» была разработана технология обмена юридически значимыми электронными документами между российскими операторами ЭДО, которая называется роуминг. Распространение этой технологии происходило медленно, потому что требовало от операторов ЭДО дополнительных финансовых вложений, стимулов к которым у них не было в силу и без того динамичного роста рынка их услуг. Сейчас развитие роуминга стимулируется за счет внешнего сетевого эффекта, который возникает при расширении числа пользователей технологий ЭДО. Однако оно по-прежнему тормозится неготовностью операторов нести дополнительные риски и расходы, делиться клиентами и трафиком, а также в связи с отсутствием устоявшейся формы организации межкорпоративного ЭДО. На текущий момент можно условно выделить несколько форм организации межкорпоративного обмена электронными документами [7. С. 25-27]:

- прямой роуминг «оператор - оператор», когда операторы ЭДО самостоятельно договариваются о настройке передачи документов между их системами;

- мультиоператорность - подключение одной компании одновременно к нескольким операторам ЭДО;
- централизованный роуминговый центр - модель взаимодействия, при которой различные операторы ЭДО могут обмениваться документами, не имея взаимных договоров «оператор - оператор».

До того момента, пока одна из этих либо новая, еще не проявившаяся форма не станет отраслевым стандартом, настройка роуминга между операторами и обеспечение совместимости стандартов будут развиваться медленными темпами.

Вернемся к рассмотрению третьей ситуации. Если между разными операторами участников обмена налажен роуминг, то единственным источником дополнительных трат будет оплата исходящего трафика (оплата за единицу пересылаемого документа по аналогии с передачей SMS-сообщений в мобильной связи). Если у этих операторов нет роуминговых соглашений, то возникают новые координационные и распределительные эффекты.

Во-первых, издержки по координации усилий контрагентов относительно организации ЭДО в условиях несовместимости стандартов электронных документов, создаваемых на разных платформах. В данной ситуации для обеих компаний возникают дополнительные трансакционные издержки, распределение которых зависит от выбранного способа решения проблемы (аналогично ситуации 2, когда один из контрагентов использует электронный документооборот, а другой - бумажный), но появляется один дополнительный вариант - совместное обращение к операторам ЭДО с запросом наладить роуминговое соединение. Еще один эффект связан с неявным кредитованием продавцом, выполнившим все обязательства, покупателя, который не производит оплату не по причине несогласия с качеством оказанных услуг или приобретенных товаров, а вследствие неудовлетворенности форматом представленных документов. Ведь, как правило, согласно условиям договоров задолженность перед поставщиком возникает после представления к оплате документов, приемлемых для покупателя.

Указанные сложности имеют не только распределительный, но и координационный эффект, от которого несут потери оба участника обмена (например, в виде дополнительных затрат труда и времени сотрудников для обеспечения взаимодействия с контрагентами). Следует упомянуть также и дополнительные издержки, которые возникают у компаний, выбирающих стратегию мультиоператорности. Поскольку величина дополнительных трансакционных издержек может превышать выгоды от использования ЭДО в конкретной сделке, то стороны договора могут и вовсе отказаться от электронных форматов и перейти к оформлению официальной документации на бумажных носителях.

В целом, вопрос совместимости стандартов электронных документов не является чисто технической сложностью в среде операторов ЭДО, и причины отсутствия стандартизации связаны с несколькими факторами, как со стороны пользователей услуг по электронной переда- 
че документов, так и со стороны разработчиков технологии и поставщиков услуг по ЭДО.

Во-первых, когда начали активно распространяться системы внутрифирменного ЭДО, возможность обмена между независимыми системами практически не рассматривалась и каждый производитель использовал свои технические стандарты создания и обработки документов. Позже, когда в 2011 г. Минфин России издал приказ №50н «06 утверждении Порядка выставления и получения счетов-фактур в электронном виде по телекоммуникационным каналам связи с применением электронной цифровой подписи», пользователи не проявили ожидаемого интереса к этой технологии (во многом по причине меньшего доверия к значимости электронных документов по сравнению с бумажными), а разрабатывать способы совместимости систем, затрачивая свои ресурсы в условиях отсутствия спроса на такие решения, производители систем посчитали нецелесообразным. Помимо этого, в условиях конкуренции каждому отдельному поставщику систем Эдо было выгоднее вытеснять по возможности другие системы, расширяя свою долю рынка, чем пытаться наладить совместимость с ними [4].

Во-вторых, сами пользователи отчасти тормозят этот процесс в отношении обмена неформализованными документами, в связи с тем что «бизнесу необходимы дополнительные поля данных и он готов за это платить, а провайдер от подобных доработок не отказывается» [3]. В итоге имеет место разнообразие форматов стандартных документов и невозможность их свободного перемещения между провайдерами, а значит, и между самими участниками обмена.

Тем не менее процесс унификации форм документов неизбежен, поскольку в условиях несовместимости стандартов технология ЭДО теряет свои ключевые преимущества, а дальнейшая стандартизация должна привести к сокращению издержек по координации действий участников обмена, распространению сетевых эффектов, позволяющих расширять круг пользователей технологиями ЭДО.

В настоящее время пользователи проявляют все больший интерес к юридически значимому ЭДО, постепенно вынуждая производителей-операторов ЭДО обеспечивать совместимость с другими системами, в связи с чем вопрос единых стандартов встает более остро.

Поскольку каждый из операторов может иметь интерес продвижения собственного стандарта, то введение стандартов способно привести к ограничению конкуренции (в условиях, когда в качестве стандарта будет принят формат работы одного из ведущих игроков на рынке услуг ЭДО, он получит преимущество, ограничивающее других конкурентов). Таким образом, предложения по стандартизации должны исходить от регулятора, что подтверждается опытом ФНС России и Минфина России по разработке стандартов электронных счетов-фактур, позволившим ввести обмен первичными финансовыми документами и сдачу бухгалтерской и налоговой отчетности в электронном формате в повседневную бизнес-практику многих организаций. При разработке стандартов регулятор должен учитывать существующий на рынке опыт по налаживанию роуминга между операторами ЭДО. Учет мнения разработчиков целесообразно организовать с привлечением их некоммерческих объединений, как например, РОСЭу. Отдельным важным моментом является : исследование международных стандартов создания и передачи электронных документов, чтобы учесть перспективы развития трансграничного ЭДО, основы которого уже заложены [2].

\section{ЗАКЛЮЧЕНИЕ}

Мы рассмотрели экономические эффекты от распространения электронного документооборота, а более детально - влияние этих технологий на трансакционные издержки межорганизационного взаимодействия. Преимущественно ЭДО оказывает положительный эффект не только на процесс документооборота, но и на бизнес-процессы организации в целом, однако следует учитывать и те издержки, которые сопряжены с его внедрением.

Способ взаимодействия с партнером в части обмена юридически значимыми документами может быть существенным фактором при заключении контракта, особенно в условиях несовпадения этих способов у участников обмена. В этих случаях на границе организаций возникает проблема выбора предпочтительного варианта документооборота и имеют место координационные и распределительные эффекты, которые во многом зависят от стратегий компаний и их переговорной силы.

Вопрос совместимости форматов электронных документов помимо технической имеет экономическую составляющую, выражающуюся в выработке отраслевого стандарта на рынке услуг операторов ЭДО и в указанных выше эффектах, возникающих в процессе контрактации. Разработка стандарта должна осуществляться регулятором с учетом опыта обеспечения совместимости у операторов ЭДО и возможных конкурентных эффектов при внедрении стандарта.

В целом, технологии межкорпоративного электронного документооборота в России, находясь на начальной стадии своего развития, не всегда позволяют достичь желаемой экономии трансакционных издержек, и эта ситуация сохранится как минимум до решения вопроса совместимости электронных документов разных операторов.

Библиографическая ссылка: Шаститко А.Е., Шпакова А.А. Электронный документооборот в контрактных отношениях // Управленец. 2018. T. 9. №5. C. 2-10. DOI: 10.29141/2218-5003-2018-9-5-1.

For citation: Shastitko A.Ye., Shpakova A.A. Electronic Document Interchange in the Contractual Relationship. Upravlenets - The Manager, 2018, vol. 9, no. 5, pp. 2-10. DOI: 10.29141/2218-5003-2018-9-5-1. 


\section{Источники}

1. Аоки М. Фирма в японской экономике. Информация, стимулирование и заключение сделок в японской экономике. СПб.: Лениздат, 1995.

2. Домрачев А.А., Евтушенко С.Н., Куприяновский В.П., Нами от Д.Е. Об инновационных инициативах государств-членов ЕАЭС в области построения глобальной цифровой экономики // International Journal of Open Information Technologies. 2016. № 9. С. 24-33.

3. Колесов А. Сможет ли Ростелеком решить проблему роуминга операторов ЭДО? URL: https://www.itweek.ru/ecm/article/detail. php?ID=186526.

4. Старков Д. Опыт использования стандартов взаимодействия СЭД (ГОСТ Р 53898 и/или МЭДО). URL: https://ecm-journal.ru/card. aspx?ContentID=5664548.

5. Шаститко А.Е. Новая институциональная экономическая теория. М.: Теис, 2010.

6. Шаститко А.Е., Павлова Н.С. Переговорная сила и рыночная власть: варианты соотношения и выводы для политики // Журнал Новой экономической ассоциации. 2017. Т. 34. № 2. С. 39-58.

7. Шпакова А.А. Межкорпоративный электронный документооборот в России: барьеры и перспективы развития // Научные исследования экономического факультета. 2017. Т. 9. Вып. 1. С. 19-36.

8. Adnan-Ariffin S., Coussins O. EDI Cost Savings Report, 2010. URL: https://www.gs1uk.org/ /media/documents/white\%20papers/ edi\%20cost $\% 20$ savings\%20report\%20\%20gs1cranfield.pdf.

9. Ahmad H.S., Bazlamit I.M., Ayoush M.D. Investigation of Document Management Systems in Small Size Construction Companies in Jordan // Procedia Engineering. 2017. Vol. 182. P. 3-9.

10. Alshibly H., Chiong R., Bao Y. Investigating the critical success factors for implementing electronic document management systems in governments: evidence from Jordan // Information Systems Management. 2016. Vol. 33. № 4. P. 287-301.

11. Hwang K.M., Lee S.J. How Does Electronic Data Interchange (EDI) affect the Competitiveness of a Firm's Supply Chain Management? // Journal of Marketing Thought. 2016. Vol. 3. №2. P. 13-19.

12. Jardini B. et al. The complexity of Electronic Data Interchange (EDI) compliance for automotive supply chain // Industrial Engineering and Engineering Management (IEEM): 2015 IEEE International Conference. IEEE, 2015. P. 361-365.

13. Koch B. Business Case. E-invoicing/E-billing. Billentis, 2017. URL: http://www.billentis.com/e-invoicing-businesscase.pdf.

14. Koch B. Global e-invoicing: How numerous Government initiatives mandate an overall change in approach to P2P automation. Billentis, 2017. URL: http://www.billentis.com/Global_e-invoicing_government_impact_on_p2p_automation.pdf.

15. North D., Wallis J. Integration Institutional Changes in Economic History. A Transaction Cost Approach // Journal of Institutional and Theoretical Economics. 1994. Vol. 150(4). P. 609-624.

16. O'Callaghan R., Kaufmann P.J., Konsynski B.R. Adoption correlates and share effects of electronic data interchange systems in marketing channels // Journal of Marketing. 1992. Vol. 56(2). P. 45-56.

17. Pho H.T., Tambo T. Integrated management systems and workflow-based electronic document management: An empirical study // Journal of Industrial Engineering and Management. 2014. Vol. 7. № 1. P. 194-217.

18. Veselá L., Radiměřský M. The development of electronic document exchange // Procedia Economics and Finance. 2014. Vol. 12. P. 743-751.

\section{References}

1. Aoki M. Firma vyaponskoy ekonomike. Informatsiya, stimulirovaniye i zaklyucheniye sdelok $v$ yaponskoy ekonomike [Information, incentives and bargaining in the Japanese economy]. St. Peterburg: Lenizdat, 1995.

2. Domrachev A.A., Yevtushenko S.N., Kupriyanovskiy V.P., Namiot D.E. Ob innovatsionnykh initsiativakh gosudarstv-chlenov EAES $\checkmark$ oblasti postroyeniya globalnoy tsifrovoy ekonomiki [On the innovative initiatives of the EAEU Member States in building a global digital economy]. International Journal of Open Information Technologies, 2016, no. 9, pp. 24-33.

3. Kolesov A. Smozhet li Rostelekom reshit' problemu rouminga operatorov EDO? [ls Rostelecom able to solve the problem of EDI operators roaming?]. Available at: https://www.itweek.ru/ecm/article/detail. php?ID=186526.

4. Starkov D. Opyt ispol'zovaniya standartov vzaimodeystviya SED (GOST R 53898 i/ili MEDO) [Using the standards of interaction of EDI]. Available at: https://ecm-journal.ru/card.aspx?ContentID $=5664548$.

5. Shastitko A.Ye. Novaya institutsionalnaya ekonomicheskaya teoriya [New institutional economics]. 4-e izd. Moscow: Teis, 2010.

6. Shastitko A.Ye., Pavlova N.S. Peregovornaya sila i rynochnaya vlast: varianty sootnosheniya i vyvody dlya politiki [Bargaining power and market power: comparison and policy implications]. Zhurnal Novoy ekonomicheskoy assotsiatsii - The Journal of the New Economic Association, 2017, vol. 34, no. 2, pp. 39-58.

7. Shpakova A.A. Mezhkorporativnyy elektronnyy dokumentooborot v Rossii: baryery i perspektivy razvitiya [Electronic document interchange in Russia: barriers and prospects of development]. Nauchnyye issledovaniya ekonomicheskogo fakulteta-Scientific Research of Economic Faculty, 2017, vol. 9, no. 1, pp. 19-36.

8. Adnan-Ariffin S., Coussins O. EDI Cost Savings Report, 2010. Available at: https://www.gs1uk.org/ /media/documents/white\%20papers/ edi\%20cost $\% 20$ savings $\% 20$ report $\% 20 \% 20$ gs 1 cranfield.pdf.

9. Ahmad H.S., Bazlamit I.M., Ayoush M.D. Investigation of Document Management Systems in Small Size Construction Companies in Jordan. Procedia Engineering, 2017, vol. 182, pp. 3-9.

10. Alshibly H., Chiong R., Bao Y. Investigating the critical success factors for implementing electronic document management systems in governments: evidence from Jordan. Information Systems Management, 2016, vol. 33, no. 4, pp. 287-301.

11. Hwang K.M., Lee S.J. How Does Electronic Data Interchange (EDI) affect the Competitiveness of a Firm's Supply Chain Management? Journal of Marketing Thought, 2016, vol. 3, no. 2, pp. 13-19.

12. Jardini B. et al. The complexity of Electronic Data Interchange (EDI) compliance for automotive supply chain. Industrial Engineering and Engineering Management (IEEM), 2015 IEEE International Conference. IEEE, 2015. Pp. 361-365.

13. Koch B. Business Case. E-invoicing/E-billing. Billentis, 2017. Available at: http://www.billentis.com/e-invoicing-businesscase.pdf.

14. Koch B. Global e-invoicing: How numerous Government initiatives mandate an overall change in approach to P2P automation. Billentis, 2017. Available at: http://www.billentis.com/Global_e-invoicing_government_impact_on_p2p_automation.pdf.

15. North D., Wallis J. Integration Institutional Changes in Economic History. A Transaction Cost Approach. Journal of Institutional and Theoretical Economics, 1994, vol. 150(4), pp. 609-624.

16. O'Callaghan R., Kaufmann P.J., Konsynski B.R. Adoption correlates and share effects of electronic data interchange systems in marketing channels. The Journal of Marketing, 1992, vol. 56(2), pp. 45-56.

17. Pho H.T., Tambo T. Integrated management systems and workflow-based electronic document management: An empirical study. Journal of Industrial Engineering and Management, 2014, vol. 7, no. 1, pp. 194-217.

18. Veselá L., Radiměřský M. The development of electronic document exchange. Procedia Economics and Finance, 2014, vol. 12, pp. 743-751. 